\title{
The Influencing Mechanism of Information Sharing Level and Inter-Firm Value Co-Creation: An Empirical Study Based on Synergy Effect
}

\author{
Qiang Liu \\ School of Management, Jinan University, Guangzhou, China \\ Email: 13229487819@163.com
}

How to cite this paper: Liu, Q. (2019) The Influencing Mechanism of Information Sharing Level and Inter-Firm Value Co-Creation: An Empirical Study Based on Synergy Effect. American Journal of Industrial and Business Management, 9, 821-833. https://doi.org/10.4236/ajibm.2019.94055

Received: March 11, 2019

Accepted: April 7, 2019

Published: April 10, 2019

Copyright $\odot 2019$ by author(s) and Scientific Research Publishing Inc. This work is licensed under the Creative Commons Attribution International License (CC BY 4.0).

http://creativecommons.org/licenses/by/4.0/

\begin{abstract}
This study explores the impact mechanism of information sharing level on inter-firm value co-creation. The author introduces the concept of inter-firm value co-creation as a dependent variable and sets the information sharing level as an independent variable. Among them, the information sharing level is divided into two measurement dimensions: information technology level and information exchange level. At the same time, synergy effect is included as an intermediary variable. It is predicted that the information sharing level will have a positive impact on inter-firm value co-creation, and the synergy effect will play a role as mediator.
\end{abstract}

\section{Keywords}

Information Sharing, Inter-Firm Value Co-Creation, Synergy Effect

\section{Introduction}

In an increasingly complex business society, each company is in a network of relationships. With the expansion of business scope and the expansion of transaction scale, more and more enterprises are facing the problem of information sharing across departments, enterprises and regions. It's common for enterprises to deal with low level of information sharing within and between enterprises.

Information sharing is considered to be an important means to effectively maximize the value of information resources. Through information sharing, it can solve the problem of information sharing and business collaboration across time and space, cross-level and cross-industry in the process of organization operation, and provide underlying support for efficient development problems.

However, information sharing is not an end. Digging up the convenience 
brought by information and helping stakeholders create value is the key. The fundamental purpose of the industrial Internet platform is to create value through information sharing. The industrial Internet platform maximizes the resources and capabilities of all entities on the platform through the interconnection of horizontal and vertical links and the information sharing of the unified platform, so that the application services can be customized to the users of all links.

Information sharing is a kind of cooperation. More and more enterprises and scholars also realize that ignoring this kind of cooperation and not paying attention to strengthening inter-firm value co-creation will lead to the loss of core competitiveness of enterprises in the future competition.

Based on this, the author realized that in the context of the industrial Internet, it is particularly important to explore the relationship between enterprise information sharing and value co-creation. Firstly, information sharing is directly subject to the development level of information technology. In recent years, global information technology has been significantly improved, so it is necessary to re-measure the level of information sharing in the new environment. Second, although many companies recognize the importance of information sharing for the development of enterprises, they still lack effective guidance and cannot truly measure the value that information sharing can create for enterprises. This study introduces the construction of inter-firm value co-creation, and divides it into four dimensions as dialogue, acquisition, risk reduction and transparency to further clarify the internal relationship. Thirdly, as part of the key link to open up, by introducing synergy effect as a mediator variable, the author attempts to open the black box between the information sharing level and the inter-firm value co-creation, and more carefully unlock the secret of this relationship chain.

This paper can be divided into five parts, the first part is the introduction of the article, the second part is the literature review, mainly introducing the research progress of related theories, the third part is the research model and hypothesis deduction of the paper, the fourth part is the empirical analysis, the fifth part is the model verification, the sixth part is the hypothesis verification, and the last part is the conclusion of the research, and points out the theoretical contribution and practical contribution.

\section{Literature Review}

\subsection{Information Sharing}

Information sharing refers to the comprehensive information sharing among various functional departments within the enterprise and between the partners in the supply chain network. It is measured by internal information sharing and external information sharing, and the external information sharing can be further extended. It is divided into information sharing capabilities with suppliers and information sharing capabilities with customers (Huo et al., 2014) [1]. Domestic scholars believe that fully realizing the information sharing and communication between enterprises on the supply chain nodes is the core measure to 
reduce the overall supply chain cost. At the same time, some scholars believe that the upstream and downstream of the supply chain can reduce the long trail effective through information sharing to improve supply chain performance and some believe that specific cooperation between enterprises helps to improve supply chain performance, and information sharing is one of the important prerequisites for cooperation and coordination. And the patterns of information sharing are classified. Zhou Ronghu's (2017) [2] research results show that the quality of information sharing and the content of information sharing will positively affect the operating performance of manufacturing enterprises. Increasing the level of information sharing by enterprises can greatly improve corporation performance. Some research results show that information technology has a certain influence on the core competitive advantage of enterprises. The way of this effect is mainly the fusion effect of information technology and organization. The effect will in turn further promote information sharing capabilities. Yuan Xumei et al. (2016) [3] studied the influence of technical ability on information sharing by constructing a structural equation model. The results show that technology application has a significant positive impact on the quality and content of information sharing, and it is suggested that enterprises in the supply chain should continue to improve. The enterprise's technical level is more efficient to achieve information sharing between enterprises.

\subsection{Synergy Effect}

In the book Corporate Strategy, Ansoff believes that synergy is the exchange of good cooperation between two or more organizations that maintains a certain degree of independence through some means. Synergy can be expressed in terms of " $2+2=5$ " (i.e., the overall effect is greater than the simple summation of individuals).

Although the concept of synergy is easy to understand and is also being studied by scholars, in practice it is very difficult for companies to achieve synergy. After analyzing a large number of cases, it was found that the success cases of synergy effect are relatively scarce, far less than failure cases.

In addition to more research on concepts, academia has also begun to explore the linkages between synergy effect and companies, such as Sirower (1997) [4] thinks that one of the main reasons for a company to implement mergers and acquisitions is to obtain synergy effect; Ying Kefu et al. (2004) [5] detailed the synergy effect in the management of enterprise groups, including organizational coordination, financial coordination, and assets. In the study of Yunjiang et al. (2006) [6], a model for the synergy effect of enterprise groups was proposed; Qiu Guodong and Bai Jingkun (2007) [7] from the perspective of value generation, proposed the theoretical analysis framework: synergy effect $=$ common effect + complementary effect + synchronization effect.

\subsection{Value Co-Creation}

Theoretical research and practical research on value co-creation has always been 
a key issue (Jian Zhaoquan et al., 2016) [8]. Value co-creation theory breaks the traditional view that companies are value creators and consumers are merely users of value. Prahalad and Ramaswamy argued that value is created by constant interaction between business and customers. The research of value co-creation theory has been carried out for more than 20 years. At present, there are two important schools in the academic world: one is based on the value of customer experience value represented by Prahalad and Ramaswamy, and the other is based the service-oriented logic to create value (Vargo and Lusch, 2004) [9]. Among them, with the continuous development of business practices in various countries, the service-oriented logic also keeps pace with the times, constantly iterating the theoretical core, and gradually forming a value-creation perspective of the service ecosystem

1) Value co-creation theory based on customer experience value

The main representative scholars of this school are Prahalad and Ramaswamy, who believe that value co-creation is an activity in which companies and customers create value through interaction. Specifically, the company is responsible for providing an experience environment for the customer's consumption experience. Customers and companies create value in creating a beautiful experience together. Value co-creation runs through the entire customer experience process. Based on this core concept, Prahalad and Ramaswamy jointly built the DART model, which suggests stimulating businesses and consumers through the four dimensions of Dialogue, Access, Risk Reduction and Transparency. Since the value comes from the customer's personal experience of the product (Prahalad, 2004) [10], in many cases even the same service, but the situation is different, it will produce different use value.

2) Value co-creation theory based on service-led logic

The important representatives of the school are Vargo and Lusch, with an emphasis on the importance of service. It points out that products are no longer a major factor in value co-creation and exchange, but that customers interact with companies in the process of using products or consumer services to create value.

3) Value co-creation based on service ecosystem

The perspective of the service ecosystem is an extension of the service-oriented logic. In the current complex network environment, this perspective has become an important research perspective of value co-creation. Vargo \& Lusch (2010) [9] put forward the view of the service ecosystem, which believes that resource interaction under complex network systems is the core of the service ecosystem.

\section{Research Model and Hypothesis}

\subsection{The Relationship between Information Sharing Level and Synergy Effect}

In the existing literature, organizational theory, economic theory and production operation management theory all believe that the lack of information and information distortion, which are two common problems in cross-organization 
communication will have a decisive impact on the achievement of synergy, further problems include three major problems of information dispersion, insufficient information and information asymmetry are bound to cause essential damage to the synergy effect of the supply chain. Collaboration requires the support of information. Information has always been considered to reduce uncertainty. Therefore, the more information is mastered, the more favorable the decision is. Therefore, improving the organization's information and data processing capabilities, efficiently integrating and sharing information, and achieving the centralization of cross-organizational behavioral decision-making, thus enhancing the information sharing effect among enterprises has become a solution to the problem.

Based on this, the study proposes the following assumptions:

H1: Enterprise information technology level has a positive impact on the synergy effect between enterprises.

H2: Enterprise information exchange level has a positive impact on the synergy effect between enterprises.

\subsection{The Relationship between Synergy and Value Co-Creation among Enterprises}

Synergy refers to the organic combination of two or more things that exert a combined effect of a simple sum of more than two things. The research content in the field of management mainly includes how to interact with each other within the organization, and how to interact with each other through certain behaviors, so as to explore the profit potential of the organization operation and maximize the benefits. According to existing research, synergy is mainly reflected in the following four aspects: 1) Production synergy, that is resource sharing across production facilities, raw materials, production technologies, etc.; 2) Technical synergy, that means multiple organizations can cooperate with the core technologies needed or jointly develop to reduce costs and risks; 3) Management synergies, it refers to management experience learning and sharing among multiple organizations; 4) Synergy between purchase and sales, organizations realize that the sharing of marketing channels, personnel, advertisements will benefit the end of the supply chain. Yunjiang (2006) [6] pointed out that in the process of value co-creation of enterprise groups, the heterogeneity between individual member companies is the foundation. On this basis, value co-creation is a synergistic effect.

Based on this, this paper proposes the following assumptions:

H3: Synergy effect between companies has a positive impact on inter-firm value co-creation.

\subsection{The Relationship between Information Sharing Level and Inter-Firm Value Co-Creation}

According to the value co-creation DART model, in the inter-firm value co-creation, it also includes four dimensions. Dialogue refers to the organiza- 
tion's daily operations, dialogue with its upstream and downstream organizations, and mutual understanding of each other's intentions and actual situations. In the inter-firm value process, Access is a platform that ensures that all stakeholders can effectively obtain the products or services or information needed by the organization from a channel perspective. The acquisition referred to at this time does not refer to ownership, but also to the right to use. In the process of value co-creation, all relevant organizations participate in the value co-creation, so they must also bear the corresponding risks. All organizations can choose to let other entities provide certain information about the risks, so as to give the other party the necessary preparation time to resist the risk, which will facilitate the continuous and orderly cooperation. Transparency is the direct premise of trust. Especially with the development of Internet information technology, the situation of information asymmetry is gradually slowing down, and the transparency between organizations will be enhanced, which will help deepen cooperation.

Based on this, this paper proposes the following assumptions:

H4: Enterprise information technology level has a positive impact on inter-firm value co-creation.

H5: Enterprise information exchange level has a positive impact on inter-firm value co-creation.

\subsection{Mediating Effect of Synergy Effect}

Strengthening information exchange and sharing among organizations, building closer cooperation, and promoting macro-industry chain synergy are also necessary conditions for all organizations in which they are involved to obtain synergies. The collaborative implementation process is based on information technology, which ensures the synchronization between enterprises. It can be said that these combined information resources will form new resources for the organization, and have value, scarcity, difficulty in imitation and irreplaceability, and help to enhance the competitive advantage of the organization. At the same time, when enterprises have good information technology, the exchange of various links in the supply chain process will have obvious positive benefits, which will help enterprises to improve their ability to absorb and understand other cooperative organizations.

Based on this, this paper proposes the following assumptions:

H6: Synergy effect plays a mediating role in the relationship between enterprise information technology level and inter-firm value co-creation.

H7: Synergy effect plays a mediating role in the relationship between enterprise information exchange level and inter-firm value co-creation.

In summary, the research model of this study is shown in Figure 1.

\section{Empirical Analysis}

\subsection{Research Background}

This research takes the industrial Internet platform as the research background. 


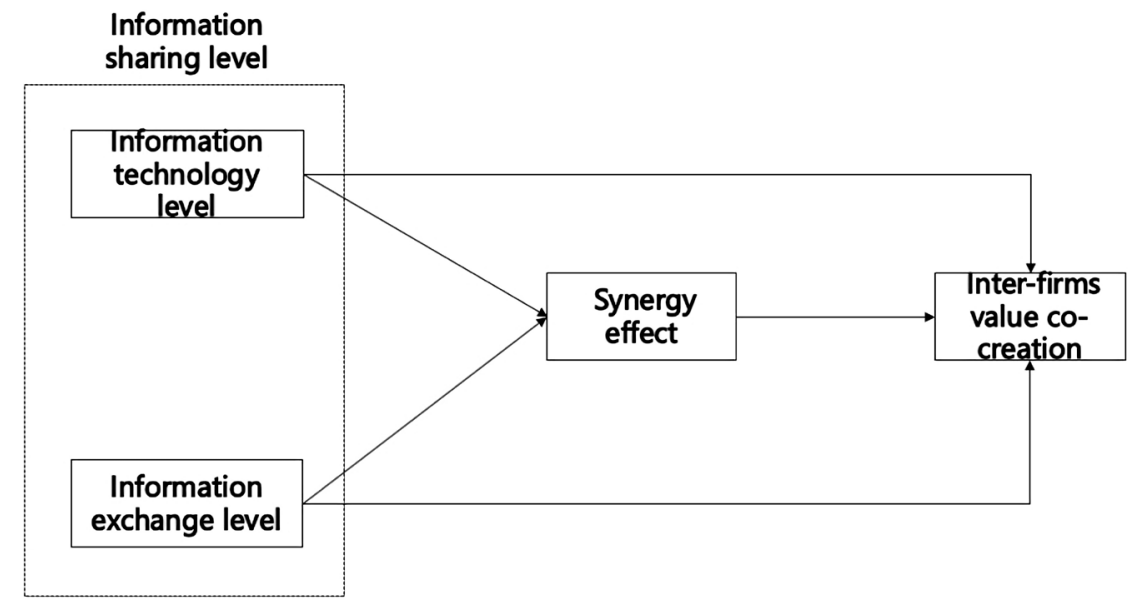

Figure 1. Research model.

The Predix cloud platform launched by GE in the United States, and the HANA big data platform developed by SAP are typical industrial big data platforms. At present, there is a certain progress in the construction of domestic industrial big data platform, mainly relying on the foundation of domestic Internet applications, and building a common platform for data access of light asset devices. This study does not limit the specific industrial Internet platform, but uses the industrial Internet platform in a broad sense as the research background.

\subsection{Scale Selection and Questionnaire Design}

All the measured variables in this study use the maturity scale developed at home and abroad, and are modified as appropriate according to the research background.

The research questionnaire consists of three main parts. First of all, in order to make the respondents better participate in the answer, the author designed a description of the questionnaire, which mainly clarified the scope of the information used in the questionnaire so that the respondent can answer according to his true feelings and ensure the authenticity of the data effectiveness. The second part is the main content of the questionnaire. From the four levels of information technology level, information exchange level, synergy effect and inter-firm value co-creation, a number of items are designed. The third part is about the collection of basic personal information, including length of service, industry, job positions, etc.

\subsection{Data Collection}

The questionnaire respondents came from five industrial Internet platform usage and research exchange groups. In general, more than $80 \%$ of the group's employees are employees of industrial Internet platform companies, and they include personnel at all levels to ensure the authenticity of the data.

The questionnaire was closed from July 10, 2018 to September 30, 2018. A total of 218 valid questionnaires were collected. 


\subsection{Data Analysis}

This study firstly uses SPSS to perform descriptive statistical analysis of the collected data, the results is as follows in Table 1, including the demographic basic information of the sample and descriptive statistical information of the measured variables.

1) Working age: $36.70 \%$ for $1-3$ years, $33.03 \%$ for 3 - 5 years, $18.35 \%$ for $5-8$ years, and $11.93 \%$ for more than 8 years.

2) Rank: $29.36 \%$ of grassroots managers, $58.72 \%$ of middle managers, and $11.93 \%$ of senior managers.

3) Gender: Males account for $85.32 \%$, and women account for $14.68 \%$.

This study used a seven-level Likert scale, a total of four variables (where the inter-firm value co-creation variables are represented by four dimensions), after testing, the valid questionnaire data collected by this study obeys a normal distribution.

\subsection{Reliability and Validity Analysis}

Reliability refers to the inherent consistency between the items of latent variables and the stability of the response measurements. According to the research situation, the author will use the Cronbach's coefficient and the combination reliability (CR) to test the reliability of the scale. In general, while the Cronbach's coefficient is above 0.8 , the reliability of the scale is believed to be good. And if the CR value is greater than 0.7 , it can be believed that the scale is acceptable.

The reliability analysis steps in this paper are as follows. First, the Cronbach coefficient values of all the measured indicators are obtained by SPSS. In the second step, the research model is run by AMOS software, and the normalized factor load of each latent variable item is obtained, and the CR value of each latent variable is calculated according to the normalized factor load. The calculation result is shown in Table 2. As can be seen from the table, all The Cronbach's coefficients of the measured indicators are all greater than 0.7 , and the $\mathrm{CR}$ values are all above 0.7 . That is to say, all the reliability analysis index values are

Table 1. Descriptive statistical results.

\begin{tabular}{ccc}
\hline Item & Option & Percentage \\
\hline \multirow{2}{*}{ Gender } & Male & $85.32 \%$ \\
& Female & $14.68 \%$ \\
Working age & $1-3$ years & $36.70 \%$ \\
& $5-5$ years & $33.03 \%$ \\
Position rank & More than 8 years & $18.35 \%$ \\
& Grassroots managers & $11.93 \%$ \\
& Middle managers & $29.36 \%$
\end{tabular}


Table 2. Reliability evaluation result of the model.

\begin{tabular}{|c|c|c|c|c|}
\hline Variable & Item & Factor load & $\begin{array}{l}\text { Cronbach's } \\
\text { coefficient }(\alpha)\end{array}$ & $\begin{array}{c}\text { Combined } \\
\text { reliability }(\mathrm{CR})\end{array}$ \\
\hline \multirow{4}{*}{ Information technology level } & IT1 & 0.695 & \multirow{4}{*}{0.832} & \multirow{4}{*}{0.779} \\
\hline & IT2 & 0.660 & & \\
\hline & IT3 & 0.744 & & \\
\hline & IT4 & 0.636 & & \\
\hline \multirow{4}{*}{ Information exchange level } & IC1 & 0.686 & \multirow{4}{*}{0.741} & \multirow{4}{*}{0.776} \\
\hline & IC2 & 0.729 & & \\
\hline & IC3 & 0.640 & & \\
\hline & IC4 & 0.668 & & \\
\hline \multirow[b]{3}{*}{ Synergy effect } & SE1 & 0.717 & \multirow{4}{*}{0.787} & \multirow{4}{*}{0.789} \\
\hline & SE2 & 0.629 & & \\
\hline & SE3 & 0.675 & & \\
\hline \multirow{14}{*}{ Inter-firm value co-creation } & SE4 & 0.758 & & \\
\hline & $\mathrm{CD} 1$ & 0.635 & \multirow{13}{*}{0.905} & \multirow{13}{*}{0.894} \\
\hline & $\mathrm{CD} 2$ & 0.627 & & \\
\hline & CD3 & 0.704 & & \\
\hline & $\mathrm{CD} 4$ & 0.670 & & \\
\hline & CA1 & 0.667 & & \\
\hline & $\mathrm{CA} 2$ & 0.534 & & \\
\hline & CA3 & 0.633 & & \\
\hline & CR1 & 0.668 & & \\
\hline & CR2 & 0.636 & & \\
\hline & CR3 & 0.687 & & \\
\hline & CT1 & 0.523 & & \\
\hline & $\mathrm{CT} 2$ & 0.536 & & \\
\hline & CT3 & 0.610 & & \\
\hline
\end{tabular}

in line with the standards recommended by experts and scholars. It is reasonable to believe that the measurement scale of this study has good reliability, that is, internal consistency.

Validity tests generally analyze convergent validity and discriminant validity. Among them, the convergence validity is also called the aggregation validity, which refers to the degree of correlation between different indicators of the same latent variable. The convergence validity is mainly tested by the average extracted variation (AVE). The scholars suggest that the AVE value of the latent variable should be above 0.5. The calculation result is shown in Table 3. This value can indicate that the latent variable explains at least $50 \%$ of the observed variable. 
Table 3. Reliability evaluation result of the model.

\begin{tabular}{cc}
\hline Variable & AVE \\
\hline Information technology level & 0.551 \\
Information exchange level & 0.539 \\
Synergy effect & 0.543 \\
Inter-firm value co-creation & 0.750
\end{tabular}

Discriminant validity refers to the degree of difference between different latentvariables. In the model of academic requirements, the values of observed variables must be clearly distinguishable. Among them, the average extracted variation (AVE) is an index often used to judge the discriminant validity. The criterion for the criterion is that the square root of the AVE value of all latent variables is greater than the correlation coefficient between the latent variable and other latent variables.

After calculation, the discriminant validity of the collected data is shown in the following Table 4 . The number on the diagonal in the table is the square root of each latent variable AVE, and the value below the diagonal is the correlation coefficient between the latent variables. It can be seen from the table that the square root of each latent variable AVE in this study is greater than the phase change coefficient between it and other latent variables. It can be shown that the model used in this study has good discriminant validity.

\section{Model Verification}

Regression analysis is a common mathematical statistical analysis used to calculate whether there is a causal relationship between variables. This study uses regression analysis to verify the relationship between enterprise information sharing level and inter-firm value co-creation, and to verify whether the mediation effect based on synergy effect is established, so as to test whether all the hypotheses in this paper are true. The calculation result is shown in Table 5 and Table 6 .

In the results of the regression analysis, the main indicators are the following:

1) $R^{2}$, used to indicate the goodness of fit of the study model.

2) F test and its Sig. value, used to indicate the validity of the regression model.

The specific analysis results are shown in the following table:

M1 measures the relationship between information technology level and synergy effect;

M2 measures the relationship between information exchange level and synergy effect;

M3 measures the relationship between synergy effect and inter-firm value co-creation;

M4 measures the impact relationship between information technology level and inter-firm value;

M5 measures the relationship between the information exchange level and inter-firm value; 
Table 4. Reliability evaluation result of the model.

\begin{tabular}{|c|c|c|c|c|}
\hline Variable & $\begin{array}{l}\text { Information } \\
\text { technology level }\end{array}$ & $\begin{array}{l}\text { Information } \\
\text { exchange level }\end{array}$ & Synergy effect & $\begin{array}{l}\text { Inter-firm value } \\
\text { co-creation }\end{array}$ \\
\hline $\begin{array}{l}\text { Information } \\
\text { technology level }\end{array}$ & 0.743 & & & \\
\hline $\begin{array}{l}\text { Information } \\
\text { exchange level }\end{array}$ & $0.550^{* *}$ & 0.734 & & \\
\hline Synergy effect & $0.657^{\star *}$ & $0.685^{\star *}$ & 0.737 & \\
\hline $\begin{array}{l}\text { Inter-firm value } \\
\text { co-creation }\end{array}$ & $0.438^{* *}$ & $0.588^{* *}$ & $0.664^{* *}$ & 0.866 \\
\hline
\end{tabular}

Note: The bold number on the diagonal indicates the square root of the AVE value of the variable, and the non-diagonal number is the correlation coefficient between the variables. ${ }^{* *}$ indicates a significant correlation at a level of $\mathrm{P}$ less than 0.01 .

Table 5. Model regression analysis statistics table.

\begin{tabular}{|c|c|c|c|c|c|}
\hline \multirow{2}{*}{ Variable } & \multicolumn{2}{|c|}{ Synergy effect } & \multicolumn{3}{|c|}{ Inter-firm value co-creation } \\
\hline & M1 & M2 & M3 & M4 & M5 \\
\hline Information technology level & $0.657^{\star \star \star}$ & - & - & $0.438^{\star * *}$ & \\
\hline Information exchange level & - & $0.685^{\star * *}$ & - & - & $0.588^{\star * *}$ \\
\hline Synergy effect & - & - & $0.664^{\star * \star}$ & - & - \\
\hline $\mathrm{R}^{2}$ & $0.432^{\star * *}$ & $0.469^{* * *}$ & $0.440^{* * *}$ & $0.191^{\star * \star}$ & 0.346 \\
\hline$\Delta \mathrm{R}^{2}$ & - & - & - & - & - \\
\hline $\mathrm{F}$ & $\begin{array}{c}80.467 \\
\star \star \star\end{array}$ & $\begin{array}{c}93.636 \\
* * *\end{array}$ & $83.404^{* * *}$ & $25.104^{\star * *}$ & $\begin{array}{c}56.119 \\
\star \star *\end{array}$ \\
\hline
\end{tabular}

Table 6. Model regression analysis statistics table (2).

\begin{tabular}{ccccc}
\hline \multirow{2}{*}{ Variable } & \multicolumn{4}{c}{ Inter-firm value co-creation } \\
\cline { 2 - 4 } & $\mathrm{M} 4$ & $\mathrm{M} 5$ & $\mathrm{M} 6$ & $\mathrm{M} 7$ \\
\hline Information technology level & $0.438^{* * *}$ & - & 0.003 & - \\
Information exchange level & - & $0.588^{* * *}$ & - & 0.252 \\
Synergy effect & - & - & $0.662^{* * *}$ & $0.491^{* * *}$ \\
$\mathrm{R}^{2}$ & $0.191^{* * *}$ & $0.346^{* * *}$ & $0.440^{* * *}$ & $0.474^{* * *}$ \\
$\Delta \mathrm{R}^{2}$ & - & - & 0.249 & 0.128 \\
$\mathrm{~F}$ & $25.104^{* * *}$ & $56.119^{* * *}$ & $41.310^{* * *}$ & $47.331^{* * *}$ \\
\hline
\end{tabular}

M6 measure the mediating role of synergy effect in the relationship between information technology level and inter-firm value co-creation;

M7 measure the mediating role of synergy effect in the relationship between information exchange level and inter-firm value co-creation.

\section{Hypothesis Testing}

According to the results of the model analysis, the verification of this study is as follows in Table 7. 
Table 7. Model hypothesis testing results.

\begin{tabular}{clc}
\hline NO. & \multicolumn{1}{c}{ Hypothesis } & Results \\
\hline H1 & $\begin{array}{l}\text { Enterprise information technology level has a positive impact on the synergy } \\
\text { effect between enterprises }\end{array}$ & proved \\
H2 & $\begin{array}{l}\text { Enterprise information exchange level has a positive impact on the synergy } \\
\text { effect between enterprises }\end{array}$ & proved \\
H3 & $\begin{array}{l}\text { Synergy effect between companies have a positive impact on inter-firm value } \\
\text { co-creation }\end{array}$ & proved \\
H4 & $\begin{array}{l}\text { Enterprise information technology level has a positive impact on inter-firm } \\
\text { value co-creation }\end{array}$ & proved \\
H5 & $\begin{array}{l}\text { Enterprise information exchange level has a positive impact on inter-firm value } \\
\text { co-creation }\end{array}$ & proved \\
H6 & $\begin{array}{l}\text { Synergy effect play a mediating role in the relationship between enterprise } \\
\text { information technology level and inter-firm value co-creation } \\
\text { H7 }\end{array}$ & $\begin{array}{l}\text { Synergy effect play a mediating role in the relationship between enterprise } \\
\text { information exchange level and inter-firm value co-creation }\end{array}$
\end{tabular}

\section{Research Conclusions}

This study mainly has the following findings: First, the two dimensions of information sharing level, including information technology level and information exchange level, will directly affect the inter-firm value co-creation, and it is positive. Second, the information sharing level will affect the inter-firm value co-creation through the achievement of synergy effect. Third, the synergy effect is influenced by information sharing level, and it is a positive correlation. At the same time, the synergy effect will directly affect the inter-firm value co-creation.

The theoretical contributions of this research are mainly as follows: Firstly, based on the mediating role of synergy effect, the mechanism of the influence of information sharing level on inter-firm value co-creation is verified. Past research has focused more on the relationship between information sharing and enterprise performance. However, enterprise performance is often just a numerical representation, and there is still a large distinction between real values. This study directly explores the impact of information sharing on inter-firm value co-creation, and has been ideally verified, extending the breadth of related research to some extent. Secondly, although synergy effect as an academic concept has been introduced into the field of management for a long time, it focuses more on qualitative analysis and less on empirical analysis. Through reviewing the literature, this study finds that synergy effect as an intermediary variable may have an impact on inter-firm value co-creation. The results show that the hypothesis is valid and the research method of this concept is expanded from the perspective of empirical research.

The practice contributions of this research are as follows: Firstly, it is clear that the enterprise wants to achieve an effective path for value co-creation between enterprises. In addition to pursuing rising financial income, the pursuit of value is constantly changing. The results of this study show that in order to 
achieve mutual value co-creation between enterprises, enterprises should pay attention to the improvement of information sharing level. The level of information sharing can be considered from two dimensions. One is the level of information technology, and the other is information exchange level. That is to say, on the one hand, the company can invest the funds to build efficient information technology tools to ensure basic communication. The second aspect is that the company should face the communication with other companies with a more active and open mind, effectively use information technology and improve the level of information openness. Secondly, the division of the four dimensions of inter-firm value co-creation including dialogue, acquisition, risk reduction and transparency, these contents are helpful to guide enterprises to establish appropriate management systems and workflow after empirical verification, so as to achieve the goal of value creation faster through clear objectives in enterprise practice.

\section{Conflicts of Interest}

The author declares no conflicts of interest regarding the publication of this paper.

\section{References}

[1] Huo, B., Zhao, X. and Zhou, H. (2014) The Effects of Competitive Environment on Supply Chain Information Sharing and Performance: An Empirical Study in China. Production \& Operations Management, 23, 552-569. https://doi.org/10.1111/poms.12044

[2] Zhou, R.H. (2017) Empirical Study on the Impact of Enterprise Information Sharing Level on Supply Chain Performance: A Case Study of Manufacturing Enterprises. China Journal of Commerce, No. 30, 170-172.

[3] Yuan, X.M. and Zhang, X. (2016) Research on the Influence of Technological Capability on the Degree of Information Sharing in Supply Chain. Journal of Industrial Technological Economics, 35, 3-8.

[4] Sirower (1997) The Synergy Trap: How Companies Lose the Acquisition Game.

[5] Ying, K.F. and Xue, H.X. (2004) Synergy Effect in Enterprise Group Management. East China Economic Management, No. 5, 135-138.

[6] Yun, J., Liu, L. and Gao, J. (2006) The Realization Mechanism of Value Creation and Synergy Effect of Enterprise Groups. Research on Financial and Economic Issues, No. 4, 79-86.

[7] Qiu, G.D. and Bai, J.K. (2007) Value Generation Analysis: A Theoretical Framework of Synergy. China's Industrial Economy, No. 6, 88-95.

[8] Jian, Z.Q., Linghu, K. and Li, L. (2016) Evolution and Prospect of Value Co-Creation Research: From the Perspective of "Customer Experience" to "Service Ecosystem". Foreign Economy and Management, 38, 3-20.

[9] Vargo, S.L. and Lusch, R.F. (2004) Evolving to a New Dominant Logic for Marketing. Journal of Marketing, 68, 1-17. https://doi.org/10.1509/jmkg.68.1.1.24036

[10] Prahalad, Ck.R.V. (2004) Co-Creating Unique Value with Customers. Strategy \& Leadership, 3, 4-9. https://doi.org/10.1108/10878570410699249 